\title{
International Journal of Medicine
}

\section{Comparison of screening tests with urine culture in urinary tract infection}

\author{
Shobha K.L ${ }^{1 *}$, Amita Shobha Rao ${ }^{1}$, Shilpa $\mathrm{K}^{2}$, Ramachandra $\mathrm{L}^{3}$ \\ ${ }^{1}$ Department of Microbiology, Melaka Manipal Medical College (Manipal Campus), Manipal University, Manipal \\ ${ }^{2}$ Department of Microbiology, Kasturba medical College, Manipal University, Manipal \\ ${ }^{3}$ Department of Surgery, Kasturba Medical College, Manipal University, Manipal \\ *Corresponding author E-mail: shobha.kl@manipal.edu
}

\begin{abstract}
Introduction: Urinary tract infection (UTI) is an important health care problem affecting millions every year. Evaluation of suspected UTI includes history, physical examination and laboratory investigations. Urine analysis for presence of pus cells, bacteria and culture are important in the adequate management of UTIs. Aim of the study was to analyze the screening tests with culture method in the diagnosis of UTI.

Materials and methods: 100 turbid midstream urine specimens collected in a sterile wide mouthed container were included in the study. Mid-stream urine specimens collected from both inpatients and outpatients attending a tertiary care hospital were included in the study. Urine specimen was subjected to Gram's staining and catalase tests and inoculated into culture medium. Semi-quantitative culture technique was followed. Organisms were identified for significant bacteriuria.

Results: Samples collected from 40 years of age and from patients more than 40 years of age were $64 \%$ and $51 \%$ were male patients. Gram's stain showed $59 \%$ of samples with organisms. Pus cells were seen in $54 \%$ of the smears and all the samples had significant growth in the medium Catalase positive was $53 \%$, all the 53 strains had growth on culture plate. E. coli was the commonest organism isolated on the culture plate. Thus screening tests like Gram's stain, pus cells detection and catalase test can be used as a rapid method to detect urinary tract infection and to start the antibiotic therapy though culture remains the gold standard method for detection of urinary tract infection.
\end{abstract}

Keywords: Gram's Staining, Pus Cells, Catalase Test, Culture Medium, Significant Bacteriuria.

\section{Introduction}

Urinary tract infection (UTI) is an important health care problem affecting millions every year. It is more common in females than males (Yan- Jun Shang et al: 2013: Shobha et al: 2005) Evaluation of suspected UTI includes history, physical examination and laboratory investigations. Urine analysis for presence of pus cells, bacteria and culture are important in the adequate management of UTIs. Processing of specimens at clinical microbiology laboratory consists of urine for culture and sensitivity testing (Guido Schmiemann et al: 2010)

Screening methods which quickly identifies the organisms from the specimens are Gram stain (GS) of urine and pyuria by microscopy. Some of the organism which does not stain by Gram's stain in the specimen may be missed during screening test but can be supported by the presence of pus cells in the urine specimen. Positive preliminary screening tests will aid to start antibiotic treatment earlier than after culture report. With this in mind an attempt was made to analyze the screening tests with culture.

\section{Materials and methods}

It was a cross sectional study. 100 turbid urine specimens collected from mid-stream urine were included in the study. Mid-stream urine specimens collected from both inpatients and outpatients attending Kasturba Medical College Hospital, Manipal were included in the study. Midstream urine samples were collected in a wide mouthed sterile container. Urine specimen was subjected to Gram's staining and catalase tests. Urine sample was also inoculated onto blood agar with four quadrant streaking method following semi quantitative culture technique using a standard loop technique (Konemann EW et al:2006).Urine culture considered positive with at least $10^{4} \mathrm{cfu} / \mathrm{mL}$ of urine with symptoms of UTI and $10^{5} \mathrm{cfu} / \mathrm{mL}$ of urine with or without symptoms. Urine was also streaked onto MacConkey's agar according to Kass concept (Baron EJ et al: 2003) for identification of lactose fermenting and nonlactose fermenting colonies. Organisms were further processed for identification by standard biochemical tests (Konemann EW et al 2006)

\section{Results}

100 samples were included in the study. Turbid urine samples were collected from different age groups showed that $64 \%$ samples were from the age group of 40 years and above (Fig1). 


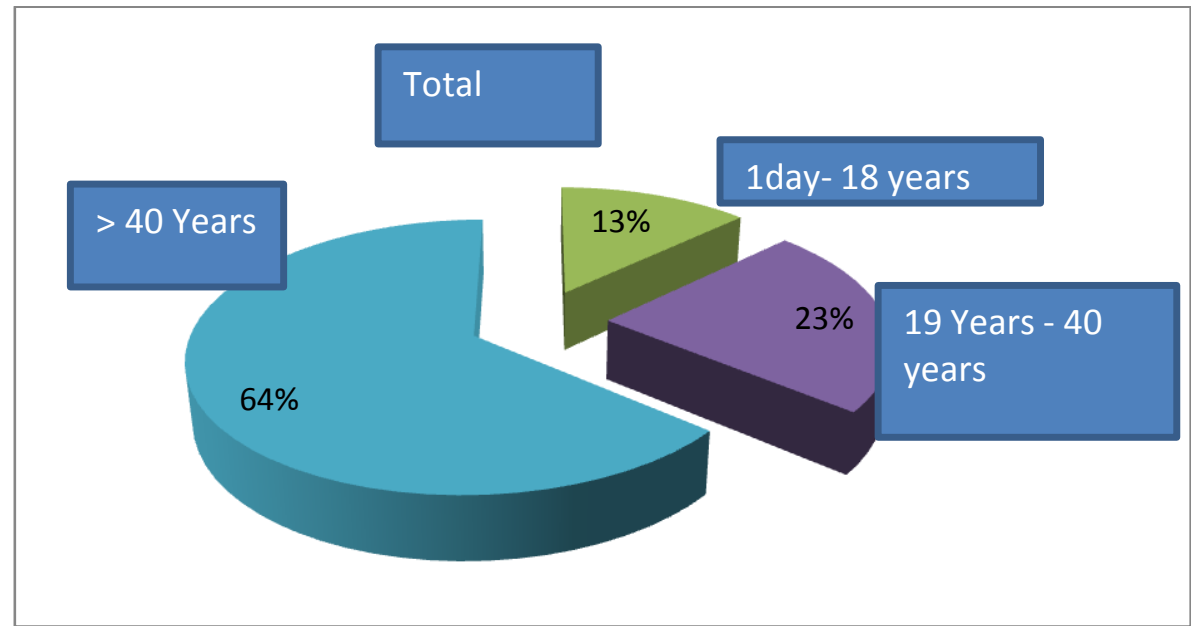

Fig. 1: Turbid Urine Samples Collected from Different Age Groups

Out of these 51 samples were from male and 49 female patients (Fig 2)

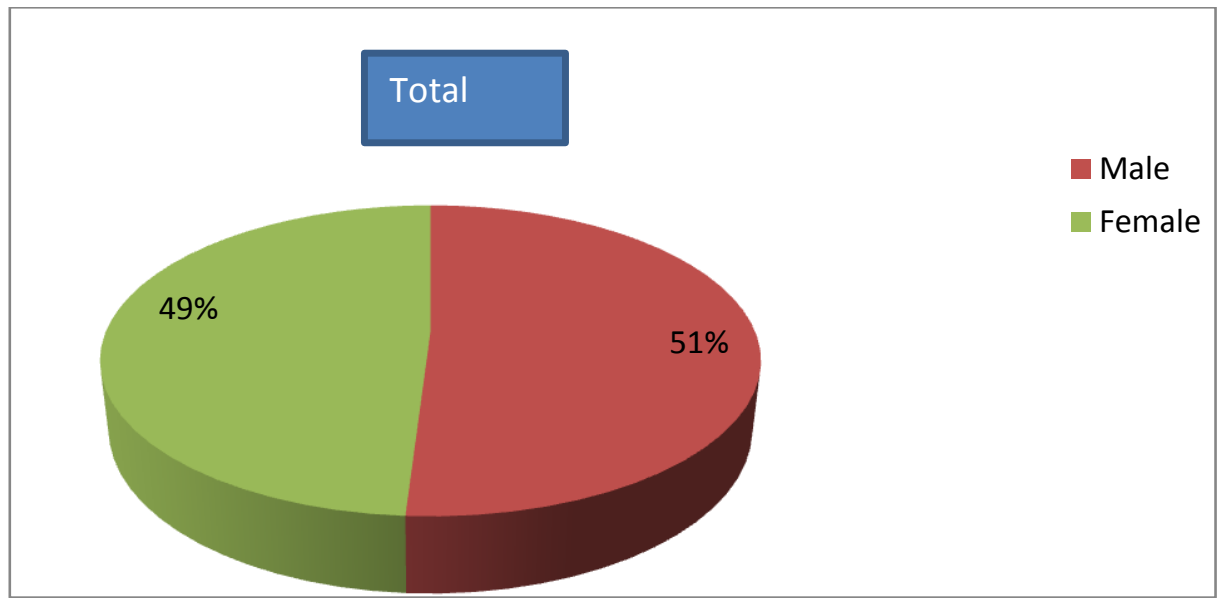

Fig. 2: Samples Collected From Male and Female Patients

Screening tests showed $59 \%$ of smears had presence of microorganisms in the Gram's stain and $41 \%$ did not have any bacteria or fungi in the smear (Table 1)

\section{Screening tests:}

Table 1: Identification of Microorganisms from Gram's Stain

\begin{tabular}{ll}
\hline Microorganisms & Number (percentage) \\
\hline Gram negative Bacillus & $55(55 \%)$ \\
Fungi (gram positive) & $4(4 \%)$ \\
No organisms identified & $41(41 \%)$ \\
\hline TOTAL & $100(100 \%)$ \\
\hline
\end{tabular}

Presence of pus cells ( 5 cells/microliter of urine) were seen in 54 specimens and 46 specimens did not show any pus cells. Catalase test was positive in $53 \%$ of the samples and negative in $47 \%$ of samples.

Colonies from the culture plates were identified for the bacteria and the yeast cells and the most common organism was E. coli followed by Klebsiella. (Table 2).

Table 2: Identification of Microorganisms from Culture Plates.

\begin{tabular}{ll}
\multicolumn{1}{c}{ Table 2: Identification of Microorganisms from Culture Plates. } \\
\hline Organisms & Number \\
\hline Escherichia coli & $38(38 \%)$ \\
Klebsiella species & $8(8 \%)$ \\
Enterobacter species & $3(3 \%)$ \\
Gram positive Oval budding Yeast cells & $4(4 \%)$ \\
suggestive of Candida species & $2(2 \%)$ \\
Enterococcus species & $1(1 \%)$ \\
Citrobacter species & $1(1 \%)$ \\
Acinetobacter species & $43(43 \%)$ \\
No growth on culture plates & $100(100 \%)$ \\
\hline TOTAL
\end{tabular}

Gram's stain showed 59 positive samples but 57 of the same samples had significant bacteriuria in culture, similarly 53 samples were catalase positive but all 53 strains had significant growth on culture plates (Table 3 ).

Table 3: Comparison of Screening Tests with Urine Culture

\begin{tabular}{lllll}
$\begin{array}{l}\text { Total } \\
\text { number: } \\
100\end{array}$ & $\begin{array}{l}\text { Microorganisms } \\
\text { in Gram's stain }\end{array}$ & $\begin{array}{l}\text { Catalase } \\
\text { test }\end{array}$ & $\begin{array}{l}\text { Pus cells in } \\
\text { urine mi- } \\
\text { croscopy }\end{array}$ & $\begin{array}{l}\text { Significant } \\
\text { bacterial } \\
\text { growth in } \\
\text { Culture } \\
\text { media }\end{array}$ \\
\hline $\begin{array}{l}\text { Positive } \\
\text { Negative }\end{array}$ & 59 & 53 & 54 & 57 \\
\hline
\end{tabular}

\section{Discussion}

In the present study $64 \%$ of them were in the age group of above 40 years and $23 \%$ belonged to the age group of $19-40$ years. Very few of them i.e., $13 \%$ were in the age group between 0-18years. This finding of the study was supported by ( P. Ayazi et al : 2010) also found that out of 153 samples collected the mean age of the infected persons were 83. The present study showed that more than half $51 \%$ of the samples from male patients and $49 \%$ of urine sample collected from female patients.

In the present study 54\% samples had showed the presence of pus cells 5 cells / microliter of urine among the turbid urine samples by microscopic examination. This study was in concordance with the study conducted by (Bertt White: 2011)

Catalase enzyme among the samples by microscopic examination out of the 100 turbid urine samples was $53 \%$ and $47 \%$ was negative for catalase test. Similar study done by (Waisman Y et al: 1999) showed $100 \%$ positivity. Comparison of Gram's stain with 
culture showed that $55 \%$ of the urine samples identified as gram negative bacteria and $4 \%$ identified as yeast cells by Gram's stain but the culture showed $53 \%$ of the samples identified as gram negative bacteria and $4 \%$ of the culture supported Candida species. 2 specimens who showed bacteria in Gram's stain but did not yield any growth, it could be due to death of the bacteria because of antibiotic therapy. Similar type of study conducted by (Marie E westwood et al: 2005, Kckhart et al 2010). All the 53\% catalase positive reactions on the urine sample grew bacteria. There are organisms which are catalase negative, but our study did not have catalase negative organisms. All the 54 smears showing pus cells grew significant bacteriuria but the smears showing yeast cells, all of them did not have pus cells. Only one of them showed pus cells. Just presence of yeast cells may not indicate urinary tract infection.

Conclusion: Thus our study shows that screening tests like Gram's stain, catalase test and pus cells detection can be used as a rapid method to detect urinary tract infection and to start the antibiotic therapy, but culture remains the gold standard method for detection of urinary tract infection. Since the sample size is small, larger number of samples is required for further confirmation.

\section{References}

[1] Yan-Jun Shang, Quin- Qian Wang, Jian-Rong Zhang, Yu-Lian Xu, Wei-Wei Zhang, Yan Chen, Ming-Li Gu, An-Mei Deng: Systematic review and meta-analysis of flow cytometry in urinary tract infection screening: Clinica Chimica Acta:2013 Vol 424: 23 September 90-95

[2] Shobha K.L, Sugandhi PRao: Prevalance of Antimicrobial resistance among Escherichia coli isolated from Urinary tract infection at Kasturba Medical Hospital, Manipal: The Antiseptics: June 2005: vol 102 No $6: 316$ - 318

[3] Guido Schmiemann, Eberhardt Knniehl, Klaus Gebhardt, Martha M Matejczyk, Eva Hummers Pradier: Diagnosis of Urinary tract infection ,A systematic review: Duetsches Arzteblatt International: May 2010:107(21): $361-367$

[4] Konemann EW, Allen SD, Janda WW et al: .Koneman's Color Atlas and textbook of diagnostic microbiology $6^{\mathrm{TH}}$ ed. 2006: (Lippin Cott Williams and Wilkins publications.

[5] Baron EJ, Pererson LR, Finegold SM (eds).Bailey and Scott's Diagnostic Microbiology, 2003: $9^{\text {th }}$ ed. Louis, USA: CV Mosby.

[6] P.Ayazi, A.Rahmani: Comparison of urine and gram stained smears of urine in diagnosis of urinary tract infections: Urology: 2010: 45-47D

[7] Bertt White: Diagnosis and treatment of urinary tract infections in children: American Fam Physician: 2001: Feb 15:83(4) 409-415.

[8] Waisman Y,Zeram E, Amirl, Mimouni M, The validity of the uriscreen test for early detection of urinary tract infection in children: Pediatrics:1999: Oct 104(4) :et41

[9] Marie E Westwood, Penny FwWhiteing, Julie Cooper. Ian S Watt, Jos Kleijnen: Further investigation of confirmed UTI in children under 5 years: a systematic review: BMC Pediatric: March 2005: 15(1)

[10]Kckhart, Lewander: Routine clinical analysis: Recent research in science and technology: 2010, 38-39. 